\title{
Oxidation of low-density lipoprotein in NIDDM: its relationship to fatty acid composition
}

\author{
E. Dimitriadis ${ }^{1,}$ M. Griffin ${ }^{2}$, D. Owens ${ }^{1}$, A. Johnson ${ }^{3}$, P. Collins ${ }^{3}$, G. H. Tomkin ${ }^{1,2}$ \\ ${ }^{1}$ Department of Clinical Medicine, Trinity College, Dublin, Republic of Ireland \\ 2 The Adelaide Hospital, Dublin, Republic of Ireland \\ ${ }^{3}$ Department of Biochemistry, Royal College of Surgeons in Ireland, Dublin, Republic of Ireland
}

Summary The increased risk of atherosclerotic disease in diabetic subjects may be due to enhanced foam cell formation following an increased susceptibility of low density lipoprotein to oxidative modification. This study has compared fatty acid content and lipoprotein oxidisability in 10 non-insulin-dependent diabetic subjects with that in 10 control subjects. Both groups were normocholesterolaemic and the diabetic subjects had higher triglyceride levels $(2.2 \pm 0.4$ vs $1.2 \pm 0.2 \mathrm{mmol} / 1, p<0.05)$. The fatty acid composition was compared in low density lipoprotein following Folch extraction, separation by thin layer chromatography (for the lipid classes) and analysis by gas liquid chromatography. Low density lipoprotein oxidisability was assessed by conjugated diene and thiobarbituric acid reacting substance formation in the presence of copper ions. The esterified/free cholesterol ratio was higher in the low density lipoprotein from patients compared to control subjects $(2.9 \pm 0.1$ vs $1.9 \pm 0.3, p<0.05)$. Linoleic acid in the cholesteryl ester fraction of the lipoprotein was higher in the patients than in the control subjects $(48.2 \pm 2.2 \%$ vs $42.4 \pm 3.4 \%, p<0.05)$ as was the total quantity of linoleic acid in the cholesteryl ester fraction $(317.8 \pm 68.0$ vs $213.2 \pm 28.0 \mu \mathrm{g} / \mathrm{mg}$ protein, $p<0.05)$ and in the low-density lipoprotein as a whole $(443.2 \pm 70.0$ vs $340.2 \pm 28.2 \mu \mathrm{g} / \mathrm{mg}$ protein, $p<0.05)$. Lipoprotein oxidisability was also increased in the diabetic group with increased formation of thiobarbituric acid reacting substances $(35.6 \pm 7.2$ vs $22.3 \pm 3.5 \mathrm{nmol} / \mathrm{mg}$ protein, $p<0.05$, increased total diene formation ( $502 \pm 60$ vs $400 \pm 30$ $\mathrm{nmol} / \mathrm{mg}$ protein, $p<0.05$ ) and increased rate of diene formation $(7.2 \pm 0.6 \mathrm{vs} 5.1 \pm 0.9 \mathrm{nmol}$ diene $\cdot \mathrm{mg}$ protein $\left.^{-1} \cdot \min ^{-1}, p<0.05\right)$. This study indicates that low-density lipoprotein from diabetic subjects is more susceptible to oxidation. This could, in vivo, accelerate foam-cell formation thereby increasing atherosclerotic risk in diabetic subjects. [Diabetologia (1995) 38: 1300-1306]

Key words Non-insulin-dependent diabetes mellitus, low-density lipoprotein oxidation, dietary fatty acids, low-density lipoprotein composition, glycated lowdensity lipoprotein.
Although hypercholesterolaemia is an important risk factor in both diabetic and non-diabetic subjects, lowdensity lipoprotein (LDL) cholesterol levels are of-

Received: 5 January 1995 and in revised form: 19 April 1995

Corresponding author: Professor G.H. Tomkin, 1 Fitzwilliam Square, Dublin 2, Republic of Ireland Abbreviations: BHT, Butylated hydroxytoluene; EDTA, ethylenediaminetetraacetic acid; TBARS thiobarbituric reacting substances; HPLC, high performance liquid chromatography; MDA, malondialdehyde; $\mathrm{HbA}_{1}$, glycated haemoglobin. ten normal in patients with atherosclerosis. In this study attention has been focused on abnormalities in the composition of LDL the major cholesterol-carrying particle, rather than the quantity. These investigations have been prompted by the finding that oxidised rather than native LDL delivers cholesterol to the macrophage [1], the precursor of the foam cell and the major cholesterol-containing cell in the atherosclerotic plaque. Therefore, the potential for LDL to be oxidised in the vessel wall may be of importance in atherogenesis. Babiy et al. [2] have shown that LDL from non-insulin-dependent diabetic (NIDDM) 
patients with hypercholesterolaemia is more easily oxidised and we have demonstrated similar findings in normocholesterolaemic NIDDM patients [3]. Several studies have shown an increase in lipid peroxidation products in diabetic subjects [4-6,], although some studies have shown no difference [7], or an increase only in diabetic subjects with complications $[8,9]$ or with poor control $[10]$ compared with control subjects. The oxidation of LDL involves the peroxidation of its polyunsaturated fatty acids [11-13,] and LDL oxidation by copper can be divided into three phases; lag phase, propogation phase and decomposition phase. During the lag phase LDL antioxidants are consumed and only minimal lipid peroxidation takes place. When antioxidants have been consumed the polyunsaturated fatty acids then become oxidised. Chisolm et al. [14] have shown that lipoprotein fractions isolated from diabetic patients had elevated levels of lipid peroxides. Several studies have investigated the fatty acid composition of plasma lipids and LDL lipids in diabetes with conflicting results. Some studies have shown lower levels of linoleic acid and higher levels of the more highly unsaturated linoleic acid metabolites, one being arachidonic acid $[15,16]$. Other studies have shown the plasma linoleic acid levels from diabetic patients to be similar to control subjects but with different levels of linoleic acid metabolites [17-19]. Peterson et al. [20] have recently shown higher proportions of linoleic acid and lower proportions of arachidonic acid and oleic acid in erythrocytes and plasma triglycerides isolated from Asian diabetic subjects compared with European diabetic subjects. However, so far few studies have examined the fatty acid composition of LDL isolated from diabetic subjects. The increased susceptibility of LDL from normocholesterolaemic diabetic patients to oxidise when compared to control non-diabetic subjects suggests that the fatty acid composition of LDL might contribute to the increase in $\mathrm{LDL}$ oxidisability. The purpose of this study was to examine the fatty acid composition of LDL in NIDDM patients and to explore the relationship between the composition of LDL and its susceptibility to oxidation.

\section{Subjects and methods}

Subjects. NIDDM subjects with normal serum cholesterol levels were randomly selected from the hospital diabetic clinic. Since plasma lipid peroxidation has been shown to be influenced by smoking [21], smokers were excluded from this study. Patients with hepatic or thyroid disease and patients with nephropathy, retinopathy and neuropathy were excluded from the study. Nine of the patients were treated with sulphonylureas and one with diet alone. Non-diabetic subjects were recruited from a pool of healthy hospital and laboratory personnel with normal serum lipid levels. All subjects gave informed consent and the study was approved by the Adelaide
Hospital Ethics Committee. More patient details are given in Table 1.

LDL isolation. Blood was collected following a 12-h fast and centrifuged at $4{ }^{\circ} \mathrm{C}$. The plasma was removed and ethylenediaminetetraacetic acid (EDTA) and butylated hydroxytoluene (BHT) were added at a concentration of $1 \mathrm{~g} / 1$ plasma and 4.4 $\mathrm{mg} / \mathrm{l}$, respectively [22]. Plasma LDL was isolated by sequential ultracentrifugation at a density range of $1.025-1.063 \mathrm{~g} / \mathrm{ml}$ [23]. LDL was stored at $4{ }^{\circ} \mathrm{C}$ in a nitrogen atmosphere in the dark for the measurement of conjugated diene and TBARS formation and LDL composition. The effect on conjugated diene lag time ( $\mathrm{min}$ ) of storing LDL for up to 7 days was examined. Lag time did not vary when LDL was stored for up to 3 days $(95 \pm 10,102 \pm 7$ and $98 \pm 5 \mathrm{~min})$ but by day 5 they were reduced (days 5 and 7 lag times were $72 \pm 8$ and $40 \pm 15 \mathrm{~min}$, respectively $n=4$ ). For the determination of vitamin $E$ and fatty acids the samples were stored for up to 8 weeks at $-20^{\circ} \mathrm{C}$. Plasma cholesterol and LDL total and free cholesterol levels were measured by enzymatic colorimetric methods (Boehringer Mannheim GmbH, Mannheim, Germany) and plasma triglycerides were measured with kits from Biomerieux (Marcy-l'Etoile, France). $\mathrm{Hb}_{1 \mathrm{c}}$ levels were determined as a percentage of total haemoglobin by an enzyme linked immunoassay where the monoclonal antibody was specific for $\mathrm{HbA}_{1 \mathrm{c}}$ (normal values $<4.9 \%$ ). Protein levels were determined by a modification of the method of Markwell et al. [24].

LDL fatty acids. Heptadecanoic acid $(100 \mu \mathrm{g})$ was added as an internal standard to LDL (1 $\mathrm{mg} / \mathrm{ml}$ of protein) and the lipids were extracted by a modification of the method of Folch et al [25]. The organic fraction was dried with anhydrous sodium sulphate. The samples were dried under nitrogen and either transmethylated [26] for total LDL fatty acid analysis or subjected to thin layer chromatography for the analysis of the fatty acids in the LDL cholesteryl ester, triglyceride and phospholipid lipid classes prior to transmethylation.

Fatty acids in LDL lipid classes. Dried extracts were redissolved in chloroform and applied to activated LK6DF S60 TLC plates (Whatman, Maidstone, U.K.) using a solvent system of petroleum ether:ethyl ether:acetic acid (80:20:0.7, $\mathrm{v}: \mathrm{v}: \mathrm{v})$ for the separation of cholesteryl ester, triglyceride and phospholipid classes. Following transmethylation of the total LDL fatty acids and the fatty acids in the LDL lipid classes, the fatty acid methyl esters were extracted after the addition of $1.3 \mathrm{ml}$ of $\mathrm{H}_{2} \mathrm{O}$ and 3 volumes of $2.5 \mathrm{ml}$ of hexane. The hexane phase was dried under nitrogen and reconstituted in iso-octane immediately prior to determination by gas liquid chromatography. The fatty acids were analysed in a Shimadzu GC-14A gas chromatograph (Kyoto, Japan) equipped with a capillary fused silica Permabond FFAP-DF-0.1 $(25 \mathrm{~m} \times 0.25 \mathrm{~mm}$ internal diameter) column (Duren, Germany). Calculations of fatty acid amounts were determined from peak area ratios of sample to internal standard with a Shimadzu CR6A Chromapac (Kyoto, Japan). The intra and inter-assay variations were 1.8 and $2.6 \%$, respectively.

LDL oxidation. LDL oxidation was measured by two methods - the formation of conjugated dienes and measurement of thiobarbituric acid-reactive substances (TBARS). The measurement of conjugated dienes was performed using a modification of the procedure described by Esterbauer et al. [27]. Oxidation of freshly prepared LDL samples $(100 \mu \mathrm{g} / \mathrm{ml})$ was initiated using $\mathrm{CuCl}_{2}(1.66 \mu \mathrm{M})$. The kinetics of lipoprotein oxidation were determined by continually monitoring the change 
in absorbance at $234 \mathrm{~nm}$ at room temperature with a SP6-500 Pye Unicam UV spectrophotometer (Cambridge, UK) attached to a Perkin Elmer (023) recorder (Cambridge, UK). Three different phases were determined [27]; the lag phase, the propagation phase and the decomposition phase. The lag phase was determined manually by drawing a tangent to the slope of the linear portion of the propagation phase and extrapolating it to the horizontal axis at time zero. The rate of LDL oxidation was determined from the propagation phase of the time course. The maximum diene concentration was determined from the $\mathrm{A}_{234}$ value represented by the points of intersection of the propagation phase line with that of the lag and decomposition phases. The concentration of dienes represented by this absorbance value was calculated from the known extinction coefficient for conjugated dienes (29500 litre $\left.\cdot \mathrm{mol}^{-1} \cdot \mathrm{cm}^{-1}\right)[28]$. The inter assay variation was $4.2 \%$. For the TBARS method LDL was diluted to a concentration of $300 \mu \mathrm{g}$ protein $/ \mathrm{ml}$ and extensively dialysed in $0.01 \mathrm{~mol} / 1$ phosphate-buffered saline ( $\mathrm{pH} 7.4$ ) and assayed as described by Buege and Aust [29]. LDL was oxidised in the presence of $10 \mu \mathrm{mol} / 1$ copper at $37^{\circ} \mathrm{C}$ in phosphate buffered saline for up to $4 \mathrm{~h}$. Oxidation was stopped at $0,1,2,3$ and $4 \mathrm{~h}$ by refrigeration to $4^{\circ} \mathrm{C}$ and the addition of $200 \mu \mathrm{mol} / 1$ EDTA and $40 \mu \mathrm{mol} / \mathrm{BHT}$. Lipid peroxidation was determined by measuring TBARS and results are expressed as malondialdehyde (MDA) equivalents using freshly prepared MDA standard. The intra-assay variation for the TBARS method $(n=6)$ was $5.9 \%$ and each assay included LDL from both the diabetic and control groups.

$L D L$ vitamin $E$. Vitamin $\mathrm{E}$ was measured by high performance liquid chromatography (HPLC) according to the method of Kaplan et al., [30]. To determine the vitamin $E$ content of LDL a- $200 \mu \mathrm{l}$ aliquot of LDL was taken and 5-mg $\alpha$-tocopherol acetate was added as an internal standard. The samples were extracted with ethanol and dried under nitrogen. The extract was reconstituted in a mobile phase which consisted of acetonitrile: methanol $(75: 25, \mathrm{v}: \mathrm{v})$ and run at a flow rate of $3.5 \mathrm{ml} /$ min. The chromatography analysis was performed with a 4.6 $\mathrm{mm}$ particle Ultracarb 5 column (, Cheshire, UK) fitted to a Shimadzu LC-6A HPLC (Kyoto, Japan) with a Shimadzu SPD-6A ultraviolet detector (Kyoto, Japan). Calculations were determined from the standard curve of peak area ratios of sample to internal standard.

$L D L$ glycation. LDL glycation was measured by affinity chromatography using aminophenyl borate gel [31]. Microcolumns containing $1 \mathrm{ml}$ of Glycogel B (Pierce Ltd, Cambridge, UK) were prepared and equilibrated with ammonium acetate buffer $(\mathrm{pH} 8.5)$. LDL $(400 \mu 1)$ was applied to the columns and non-glycated LDL was washed off with $10 \mathrm{ml}$ of the same buffer. Glycated LDL, which adheres to the gel, was subsequently eluted with $4 \mathrm{ml}$ of sorbitol buffer ( $\mathrm{pH} 8.5$ ). Glycated LDL was expressed as a percentage of total LDL.

\section{Statistical analysis}

Statistical analysis was performed using Student's $t$-test or analysis of variance (ANOVA). Correlation coefficients are determined by linear regression analysis. Results were expressed as mean \pm SEM and values of less than 0.05 were considered to be statistically significant.
Table 1. Patient characteristics, plasma lipoproteins and LDL composition

\begin{tabular}{lcc}
\hline & $\begin{array}{l}\text { Diabetic } \\
\text { patients }\end{array}$ & $\begin{array}{c}\text { Control } \\
\text { subjects }\end{array}$ \\
\hline Number & 10 & 10 \\
Age & $69 \pm 10$ & $63 \pm 10$ \\
Sex ratio (female/male) & $5 / 5$ & $6 / 4$ \\
BMI $\left(\mathrm{kg} / \mathrm{m}^{2}\right.$ ) & $27.4 \pm 2.9^{\mathrm{a}}$ & $22.5 \pm 0.2$ \\
Serum triglyceride (mmol/1) & $2.2 \pm 0.4^{\mathrm{a}}$ & $1.2 \pm 0.2$ \\
Serum cholesterol (mmol/1) & $5.3 \pm 0.5$ & $5.1 \pm 0.4$ \\
LDL glycation (\%) & $4.6 \pm 0.33^{\mathrm{b}}$ & $2.2 \pm 0.11$ \\
LDL esterified/free cholesterol & & \\
(ratio) & $2.9 \pm 0.12^{\mathrm{b}}$ & $1.9 \pm 0.26$ \\
LDL vitamin E & & \\
(nmol/mg LDL protein) & $268 \pm 15$ & $255 \pm 23$ \\
\hline
\end{tabular}

Mean \pm SEM

${ }^{\mathrm{a}} p<0.05,{ }^{\mathrm{b}} p<0.01$ with respect to control subjects

\section{Results}

The subjects were of a similar age but the diabetic patients were significantly more obese with a body mass index (BMI of $27.4 \pm 2.9 \mathrm{~kg} / \mathrm{m}^{2}$ as shown in Table 1 . Serum triglycerides were higher in the diabetic group $(2.2 \pm 0.4 \mathrm{mmol} / 1)$ compared to the control group $(1.2 \pm 0.2 \mathrm{mmol} / \mathrm{l})(p<0.05)$. The diabetic patients were moderately well controlled $\left(\mathrm{HbA}_{1 \mathrm{c}}=\right.$ $7.3 \pm 0.8 \%)$ and the esterified to free cholesterol ratio in LDL was significantly higher in the diabetic group ( $2.9 \pm 0.12$ vs $1.9 \pm 0.26, p<0.01$, Table 1$)$. The vitamin $E$ content was not significantly different between the groups (Table 1). A significant increase was seen in the percentage of glycated LDL in the diabetic patients compared to the control group $(4.6 \pm 0.33$ vs $2.2 \pm 0.11 \%, p<0.01)$. Total fatty acids in the LDL particle did not differ significantly between the groups, although there was a slight increase in the percentage of both linoleic acid and arachidonic acid in the diabetic subjects; however, when expressed as $\mu \mathrm{g} / \mathrm{mg}$ LDL protein there was a significantly higher linoleic acid/LDL protein in the diabetic patients $(443.2 \pm 70$ vs $340.2 \pm 28.2, p<0.05)$ (Table 2). The levels of the main unsaturated fatty acids in the three lipid classes - cholesteryl esters, triglycerides and phospholipids are shown in Table 3. There was a significantly greater percentage of linoleic acid in the cholesteryl ester class in the diabetic patients compared to the control group $(48.2 \pm 2.2$ vs $42.8 \pm 3.4 \%, p<0.05)$ and there was also more arachidonic acid in their cholesteryl esters although this did not reach statistical significance (Table 3). Cholesterol linoleate, expressed as $\mu \mathrm{g}$ cholesteryl linoleate/mg LDL protein was also significantly higher in the diabetic patients $317.8 \pm 68.0$ vs $213.2 \pm 28.0 \mu \mathrm{g} / \mathrm{mg}$ LDL protein $(p<0.05)$.

LDL oxidisability was measured by two different methods and a significant increase was found in both the formation of TBARS and conjugated dienes in 
Table 2. Percent of total fatty acids in LDL

\begin{tabular}{|c|c|c|c|c|}
\hline \multirow[t]{2}{*}{ Fatty acid } & \multicolumn{2}{|l|}{ Diabetic patients } & \multicolumn{2}{|l|}{ Control subjects } \\
\hline & $\%$ total LDL fatty acids & $\mu \mathrm{g} / \mathrm{mg}$ LDL protein & $\%$ total LDL fatty acids & $\mu \mathrm{g} / \mathrm{mg} \mathrm{LDL}$ protein \\
\hline $16: 0$ & $22.3 \pm 1.1$ & $243.5 \pm 26.5$ & $22.8 \pm 1.2$ & $190.5 \pm 26.2$ \\
\hline $18: 0$ & $9.9 \pm 1.7$ & $96.2 \pm 8.5$ & $9.0 \pm 1.3$ & $84.6 \pm 6.1$ \\
\hline $18: 1$ & $19.1 \pm 1.8$ & $183.7 \pm 20.1$ & $17.2 \pm 1.6$ & $163.3 \pm 11.1$ \\
\hline $18: 2$ & $39.8 \pm 1.2$ & $443.2 \pm 70.7^{a}$ & $41.5 \pm 2.2$ & $340.2 \pm 28.2$ \\
\hline
\end{tabular}

Mean \pm SEM

${ }^{\mathrm{a}} p<0.05$ with respect to control subjects

Table 3. Fatty acid composition in LDL lipid fractions (\%)

\begin{tabular}{|c|c|c|c|c|c|c|}
\hline \multirow[t]{2}{*}{ Fatty acid } & \multicolumn{2}{|c|}{ Cholesteryl ester } & \multicolumn{2}{|c|}{ Triglyceride } & \multicolumn{2}{|c|}{ Phospholipid } \\
\hline & $\begin{array}{l}\text { Control } \\
\text { subjects }\end{array}$ & $\begin{array}{l}\text { Diabetic } \\
\text { patients }\end{array}$ & $\begin{array}{l}\text { Control } \\
\text { subjects }\end{array}$ & $\begin{array}{l}\text { Diabetic } \\
\text { patients }\end{array}$ & $\begin{array}{l}\text { Control } \\
\text { subjects }\end{array}$ & $\begin{array}{l}\text { Diabetic } \\
\text { patients }\end{array}$ \\
\hline $16: 1$ & $4.9 \pm 0.8$ & $4.5 \pm 0.6$ & $1.2 \pm 0.4$ & $2.6 \pm 0.9$ & $0.8 \pm 0.2$ & $1.0 \pm 0.3$ \\
\hline $18: 0$ & $3.8 \pm 0.6$ & $4.0 \pm 1.3$ & $8.1 \pm 2.2$ & $6.5 \pm 1.9$ & $16.5 \pm 2.8$ & $17.5 \pm 2.0$ \\
\hline $18: 1$ & $29.1 \pm 4.2$ & $24.0 \pm 3.1$ & $46.4 \pm 4.8$ & $42.7 \pm 3.8$ & $17.4 \pm 1.8$ & $17.8 \pm 1.4$ \\
\hline
\end{tabular}

Mean \pm SEM

${ }^{a} p<0.05$ with respect to control subjects

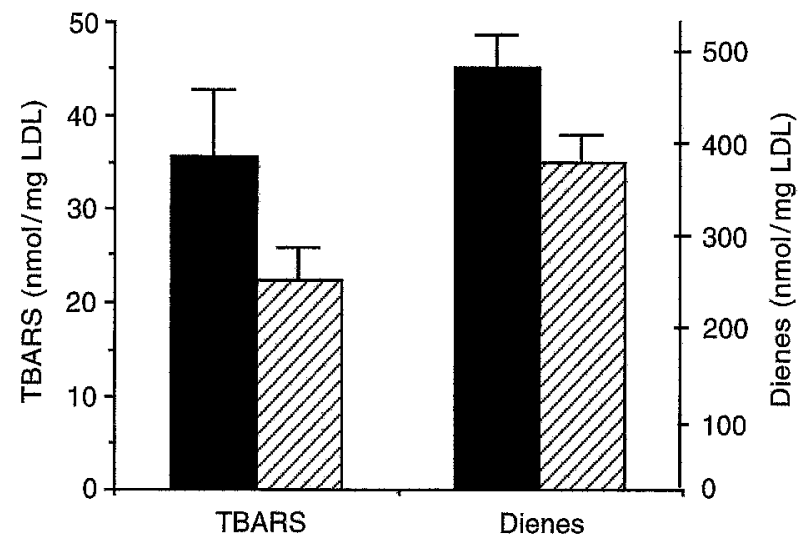

Fig. 1. LDL oxidation in non-diabetic $\square(n=10)$ and non-diabetic subjects $(n=10)$. LDL oxidisability was determined by two methods under copper-induced stress. The formation of thiobarbituricacid reacting substances (TBARS) was significantly higher in the diabetic group and the total amount of conjugated dienes formed over a 5 -h time period was significantly higher in the diabetic group compared to the control group (both $p<0.05$ )

the diabetic patients (Fig. 1). Both the TBARS produced (35.2 $\pm 7.2 \mathrm{vs} 22.3 \pm 3.5 \mathrm{nmol} / \mathrm{mg}$ LDL protein, $p<0.05)$ and the total amount of conjugated dienes produced (502 \pm 60 vs $400 \pm 30 \mathrm{nmol} / \mathrm{mg}$ LDL protein, $p<0.05)$ were significantly greater in the diabetic group compared to the control group as shown in Figure 1. The conjugated diene lag time was shorter in the diabetic patients compared to the control group ( $84 \pm 19$ vs $125 \pm 15 \mathrm{~min}, p<0.05$ ) and the rate of increase in diene formation was greater in the diabetic patients $(7.22 \pm 0.6$ vs $5.05 \pm 0.9 \mathrm{nmol}$ dienes $\cdot \mathrm{mg} \mathrm{LDL}-1 \cdot \mathrm{min}^{-1}, p<0.05$ ) (Fig. 2). The relationship between LDL fatty acid composition and oxidisability was examined (Fig. 3). There was a significant positive correlation between the percentage of linoleic acid in the LDL cholesteryl ester fraction and the maximum amount of dienes produced $(r=0.87, p<0.01)$. The LDL esterified-to-free cholesterol ratio also significantly correlated with the percentage of linoleic acid in the cholesteryl ester fraction of LDL ( $r=0.69, p<0.01)$ (Fig. 4) but no significant relationship was found with LDL glycation and linoleic acid.

\section{Discussion}

There is evidence to suggest that the oxidation of LDL is important in the atherosclerotic process. Free radical production is increased in diabetes suggesting an increased potential for oxidation of LDL in diabetic patients [4]. We have previously demonstrated an increased esterified/free cholesterol ratio in LDL from NIDDM patients[3] which was related to an increased LDL oxidisability. The present study demonstrates that an increased LDL oxidisability, measured as the formation of conjugated dienes, in the diabetic patient is related to an increase in the percentage of linoleic acid in the LDL cholesteryl ester in these patients. The reason why diabetic patients 

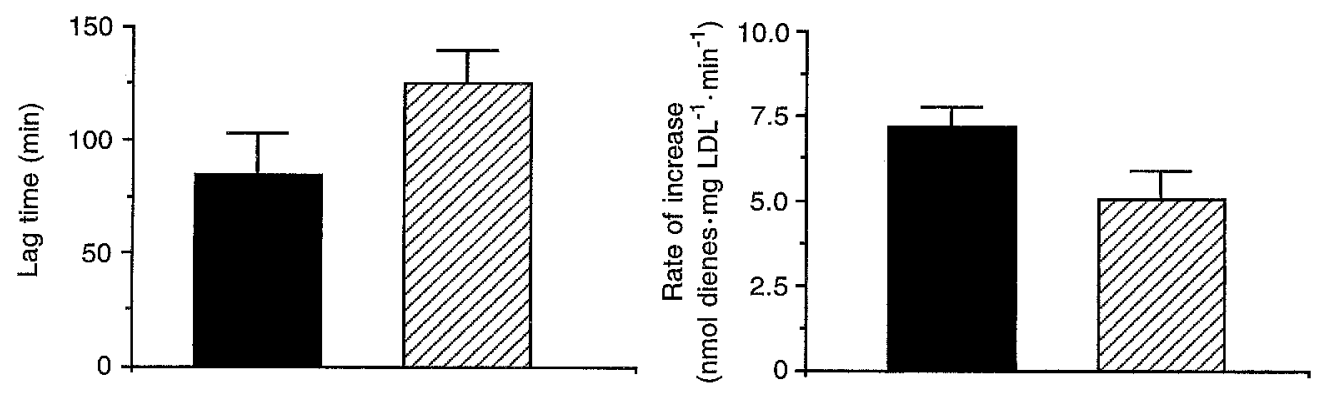

Fig. 2. Susceptibility of LDL from diabetic patients and control subjects to copperinduced oxidation measured by conjugated diene formation. Conjugated diene lag time was significantly shorter and rate of increase in diene formation significantly greater (both $p<0.05)$ using LDL from the diabetic patients

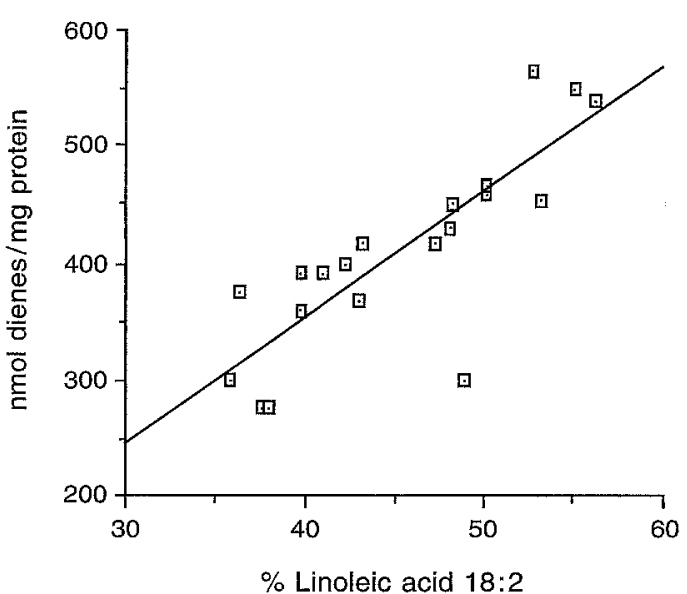

Fig. 3. Correlation was found between the maximum amount of conjugated dienes produced and the percentage of linoleic acid in the LDL of the subjects studied $(n=20), r=0.87$, $p<0.05$

have an increased linoleic acid in the LDL cholesteryl ester is uncertain but it may be due to diet. Dietary advice for the diabetic patient has usually been to decrease saturated fat, and to increase polyunsaturated fat and this has been shown to increase serum linoleic acid [32]. Furthermore, a recent study by Laitinen et al. [33] showed that the serum fatty acid composition of recently-diagnosed diabetic patients could be changed by diet therapy. The increase may also be related to an impairment in the activity of the insulin sensitive $\Delta-6$ desaturase in diabetes [18]. This enzyme is responsible for the initial step in the metabolism of linoleic acid via $\gamma$-linolenic acid to arachidonic acid. Reaven et al. [34] showed that the extent of LDL oxidation is strongly influenced by the LDL linoleic acid content. More recently, dietary studies have shown that the enrichment of LDL linoleic acid by dietary manipulation resulted in an increase in oxidisability [35, 36]; our results confirm those findings. The diabetic subjects in this study had a raised percentage of linoleic acid in their cholesteryl ester and this positively correlated with oxidisability.

Lipid peroxidation is a complex non-linear process [37] and methods of in vitro oxidation measure different stages of lipid peroxidation. In the present study, two methods were used to measure the oxidisability of LDL under copper-induced stress. In our study

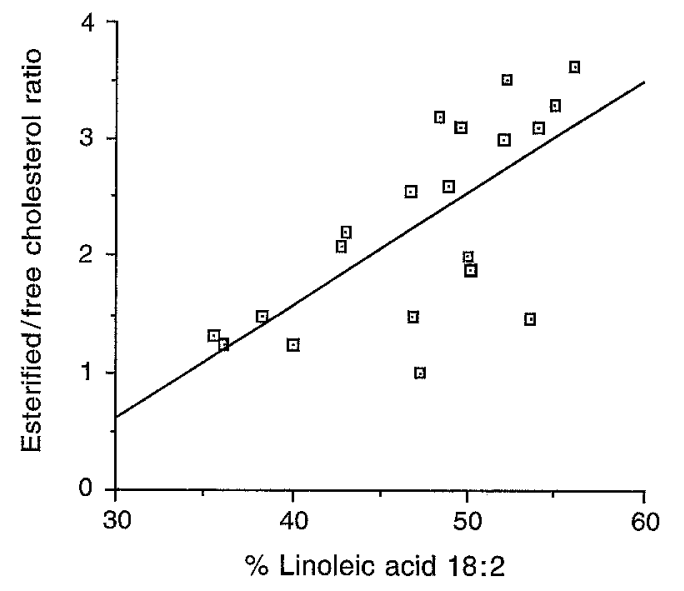

Fig.4. A significant positive correlation was found between the esterified/free cholesterol ratio and the percentage of linoleic acid in the LDL cholesteryl ester fraction, $(n=20)$, $r=0.69, p<0.05$

the lag time for LDL oxidation was shorter than in LDL from control subjects in spite of similar vitamin $E$ levels suggesting that the fatty acid composition of the LDL does have an effect on the initiation phase. The rate of increase in diene formation was also significantly greater in LDL from the diabetic patients which would be expected because of the greater amount of available substrate present. In LDL from non-diabetic subjects the rate of increase during the propogation phase has been shown previously to be related to fatty acid composition of LDL [34]. The formation of conjugated dienes is an early step in lipid peroxidation and is dependent on the fatty acid composition and the endogenous antioxidants [38]. The TBARS assay measures MDA which is an endstage product of lipid peroxidation, and can be used as an indicator of oxidation. The MDA is formed from fatty acids with more than two double bonds [37]; thus, in LDL linoleic acid having two double bonds is not a potential source of MDA as is arachidonic acid. Therefore, the TBARS assay can be used as an indicator of oxidation but, to get a more complete picture, other methods for measuring oxidation should also be used. Öhrvall [39] recently showed a negative correlation with MDA and linoleic acid; however, they showed a positive correlation with arachidonic acid and $\gamma$-linolenic acid in serum lipo- 
protein lipids. This result would be expected according to Esterbauer et al. [37] since MDA is formed from fatty acids with more than two double bonds. Glycation of LDL has previously been shown to be related to the oxidisability of LDL [40]. In this study we failed to find such a correlation possibly because there was little variation in the range of $\mathrm{HBA}_{1 \mathrm{c}}$ and LDL glycation values in the diabetic patients studied and this may also be a reason for the lack of correlation with LDL linoleic acid.

Oxidative susceptibility of LDL has been shown to be increased in the most dense of three LDL subfractions $[22,41,42]$ demonstrating an increased susceptibility to oxidative modification of small dense LDL in patients with atherogenic lipoprotein phenotype pattern B. Analysis of the composition of small dense LDL was not shown in these papers. The present study suggests that the small dense LDL, a cholesterol-rich particle, is more easily oxidisable due to the increased polyunsaturated fatty acids. This is supported by a significant increase in linoleic acid in LDL isolated from diabetic subjects as shown in Table 2 . It is likely that the increased oxidisability of LDL occurred in the small dense particles which are known to be increased in diabetes [43]

This study suggests that even though diabetic subjects may be under fairly reasonable control important factors such as LDL core fatty acid composition should be examined because of the possibility of enhanced oxidisability of this lipoprotein with its ensuing implications for foam-cell formation.

Acknowledgements. The authors wish to thank the European Association for the Study of Diabetes for their financial support of the project.

\section{References}

1. Sparrow CP, Parthasarathy BS, Steinberg D (1989) A macrophage receptor that recognizes oxidised low density lipoprotein but not acetylated low density lipoprotein. J Biol Chem 264: 2599-2604

2. Babiy AV, Gebicki JM, Sullivan DR, Willey K (1992) Increased oxidisability of plasma lipoproteins in diabetic patients can be decreased by probucol therapy and is not due to glycation. Biochem Pharmacol 43: 995-1000

3. Bowie A, Owens D, Collins P, Johnson A, Tomkin GH (1993) Glycosylated low density lipoprotein is more sensitive to oxidation: implications for the diabetic patient? Atherosclerosis 102: 63-67

4. Kaji H, Jurasaki M, Ito K et al. (1985) Increased lipoperoxide value and glutathione activity in blood plasma of type 2 (non-insulin-dependent) diabetic women. Klin Wochenschr 63: 765-768

5. Donnelly JP, McGrath LT, Brennan GM (1993) Lipid peroxidation, LDL glycosylation and dietary fish oil supplementation in type II diabetes mellitus. Biochem Soc Trans 22: $34 \mathrm{~S}$

6. Katoh K (1992) Possible relevance of lipid peroxidation and thromboxane production to the initiation and/or evolu- tion of microangiopathy in non-hyperlipidemic type 2 diabetes mellitus. Diab Res Clin Pract 18: 89-98

7. Velazquez E, Winocour PH, Kesteven P, Alberti KGMM, Laker MF (1991) Relation of lipid peroxides to macrovascular disease in type 2 diabetes. Diabet Med 8: 752-758

8. Mooradian AD (1991) Increased serum conjugated dienes in elderly diabetic patients. Am Ger Soc 39: 571-574

9. Jennings PE, Jones AF, Florkowski CM (1978) Increased diene conjugates in diabetic subjects with microangiopathy. Diabet Med 4: 452-456

10. Altomare E, Vendemiale G, Chicco D, Procacci V, Cirelli F (1992) Increased lipid peroxidation in type 2 poorly controlled diabetic patients. Diabete Metab 18: 264-271

11. Steinbrecher UP (1987) Oxidation of human low density lipoproteins results in derivitisation of lysine residues of apolipoprotein B by lipid peroxide decomposition products. J Biol Chem 262: 3603-3608

12. Esterbauer H, Jurgens G, Quenhenberger O, Koller E (1987) Auto-oxidation of human low density lipoprotein: loss of polyunsaturated fatty acids and vitamin $\mathrm{E}$ and generation of aldehydes. J Lipid Res 28: 495-509

13. Lenz ML, Hugh H, Mitchell JR et al. (1990) Lipid hydroperoxy- and hydroxy-derivatives in copper-catalysed oxidation of low density lipoproteins. J Lipid Res 319: $1043-1050$

14. Chisolm GM, Irwin KC, Penn MS (1992) Lipoprotein oxidation and lipoprotein-induced cell injury in diabetes. Diabetes 41[Supp1 2]:61-66

15. Salomma V, Ahola I, Tuomilehto J, Aro A, Pietinen P, Korhonen HJ (1990) Fatty acid composition of serum cholesterol esters in different degrees of glucose intolerance: a population-based study. Metabolism 39: 1285-1291

16. Pelikanova T, Kohout M, Valek J, Base J, Stefka Z (1991) Fatty acid composition of serum lipids and erythrocyte membranes in type 2 (non-insulin-dependent) diabetic men. Metabolism 40: 175-180

17. Tivlis RS, Taskinen MR, Miettinen TA (1988) Effect of insulin treatment on fatty acids of plasma and erythrocyte membrane lipids in type 2 diabetes. Clin Chim Acta 171: 293-304

18. VanDoomaal JJ, Idema IG, Muskiet FAJ (1988) Effects of short-term high dose intake of evening primrose oil on plasma and cellular fatty acid compositions, a-tocopherol levels and erythropoietin in normal and type 1 (insulin-dependent) diabetic men. Diabetologia 31: 576-584

19. Takahashi R, Moriata I, Saito Y, Murota S (1984) Increased arachidonic acid incorporation into platelet phospholipids in type 2 (non-insulin-dependent) diabetes. Diabetologia 26: $134-137$

20. Peterson DB, Fisher K, Carter RD, Mann J (1994) Fatty acid composition of erythrocytes and plasma triglyceride and cardiovascular risk in Asian diabetic patients. Lancet 343: $1528-1530$

21. Harats D, Ben-Naim M, Dabach Y, Hollander G, Stein O, Stein Y (1989) Cigarette smoking renders LDL susceptible to peroxidative modification and enhanced metabolism by macrophages. Atherosclerosis 79: 245-252

22. De Graff J, Hendriks JCM, Demacker PNM, Stalenhoef AF (1993) Identification of multiple dense LDL subfractions with enhanced susceptibility to in vitro oxidation among hypertriglyceridaemic subjects. Arterioscler Thromb 1993 13: 712-719

23. Havel RA, Eder HM, Bragdon JH (1985) The distribution and chemical composition of ultracentrifugally separated lipoproteins in human serum. J Clin Invest 34: 1345-1353

24. Markwell MAK, Hass SM, Bieber LL, Tolbert NE (1978) A modification of the Lowry procedure to simplify protein 
determination in membrane and lipoprotein samples. Anal Biochem 87: 206-210

25. Folch J, Lees M, Sloane S G H (1957) A simple method for the isolation and purification of total lipids from animal tissues. J Biol Chem 226: 479-509

26. Sattler W, Puhl H, Kostner GM, Esterbauer H (1991) Determination of fatty acids in the main lipoprotein classes by capillary gas chromatography: BF3/Methanol transesterification of lyophilised samples instead of Folch extraction gives higher yields. Anal Biochem 198: 184-190

27. Esterbauer H, Striegel G, Puhl H, Kothender M (1989) Continuous monitoring of in vitro oxidation of human low density lipoproteins. Free Radical Res Commun 6: 67-75

28. Croft KD, Williams P, Dimmitt S, Abu-Amsha R, Beilin LJ (1995) Oxidation of low density lipoproteins: effect of antioxidant content, fatty acid composition and intrinsic phospholipase activity on susceptibility to metal ion-induced oxidation. Biochim Biophys Acta 1254: 250-256

29. Buege JA, Aust SD (1978) Microsomal lipid peroxidation. Methods Enzymol 52: 302-310

30. Kaplan LA, Miller JA, Stein EA (1987) Simultaneous measurement of serum retinol, tocopherols, carotenes and carotenoids by high performance liquid chromatography. J Clin Lab Anal 1: 147-152

31. Jack CM, Sheridan B, Kennedy L, Stout RW (1988) Nonenzymatic glycosylation of low density lipoproteins. Results of an affinity chromatography method. Diabetologia 31: $126-127$

32. Parfitt VJ, Desomeaux K, Bolton CH, Hartog M (1993) Effects of high monounsaturated and polyunsaturated fat diets on plasma lipoproteins and lipid peroxidation in type 2 diabetes mellitus. Diabet Med 11: 85-91

33. Laitinen JH, Ahola IE, Sarkkinen ES, Winberg RL, Harmaakorpi-Ilvonen PA, Uusitupa MI (1993) Impact of intensified diet therapy on energy and nutrient intakes and fatty acid composition of serum lipids in patients with recently diagnosed non-insulin-dependent diabetes mellitus. J Am Diet Assoc 93: 276-283
34. Reavan P, Parthasarathy S, Grasse BJ et al. (1991) Feasibility of using an oleate-rich diet to reduce susceptibility of low-density lipoprotein to oxidative modification in humans. Am J Clin Nutr 54: 701-706

35. Reaven P, Parthasarathy S, Grass BJ, Miller E, Steinberg D (1993) Effects of oleate-rich and linoleate-rich diets on susceptibility of low density lipoproteins to oxidative modification in mildly hypercholesterolemic subjects. J Clin Invest 9: 668-676

36. Bonanome A, Pagnan A, Biffanti S et al. (1992) Effect of dietary monounsaturated and polyunsaturated fatty acids on the susceptibility of plasma low density lipoproteins to oxidative modification. Arterioscler Thromb 12:529-533

37. Esterbauer H, Gebicki J, Puhl H, Jurgens G (1992) The role of lipid peroxidation and antioxidants in the oxidative modification of LDL. Free Radical Biol Med 13(4):341-350

38. Witztum JL (1991) The role of oxidised LDL in atherosclerosis. Adv Exp Med Biol 285: 353-365

39. Öhrvall M, Tengblad S, Ekstrand B, Siegbahn A, Vessby B (1994) Malondialdehyde concentration in plasma is inversely correlated to the proportion of linoleic acid in serum lipoprotein lipids. Atherosclerosis 108: 103-110

40. Hunt J, Smith CCT, Wolff SP (1990) Autoxidative glycosylation and possible involvement of peroxides and free radicals in LDL modification by glucose. Diabetes 39: 14201424

41. Tribble DL, Holl LG, Wood PD, Krauss RM (1992) Variation in oxidative susceptibility among six low density lipoprotein subfractions of differing density and particle size. Atherosclerosis 93: 189-199

42. Chait A, Brag R, Tribble DL, Krauss RM (1993) Susceptibility of small dense low-density lipoproteins to oxidative modification in subjects with the atherogenic lipoprotein phenotype, pattern B. Am J Med 94: 350-355

43. Feingold KR, Grunfeld C, Pang M, Doerrler W, Krauss RM (1992) Subclass phenotypes and triglyceride metabolism in non-insulin-dependent diabetes. Arterioscler Thromb 12: 1496-1.502 